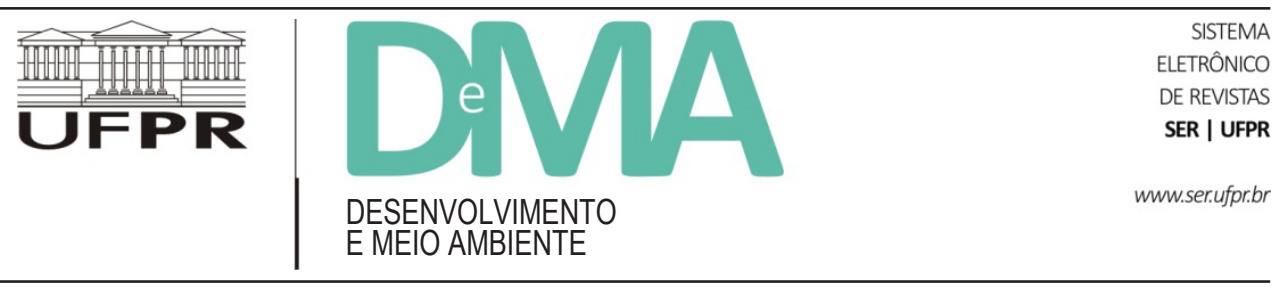

\title{
As percepções sobre as variações e mudanças climáticas e as estratégias de adaptação dos agricultores familiares do Seridó potiguar
}

\section{The Perception about Climatic Variations and Changes, and the Adaptation Strategies of the Family Farmers from Serido, Rio Grande do Norte, Brazil}

\author{
Anna Jéssica Pinto de ANDRADE ${ }^{1 *}$, Neusiene Medeiros da SILVA ${ }^{1}$, Cimone Rozendo de SOUZA $^{1}$ \\ ${ }^{1}$ Universidade Federal do Rio Grande do Norte (UFRN), Natal, RN, Brasil. \\ *E-mail de contato: jessyandrade@hotmail.com
}

Artigo recebido em 4 de agosto de 2013, versão final aceita em 20 de junho de 2014.

RESUMO

As mudanças climáticas podem tornar mais escassos os recursos naturais das regiões semiáridas do planeta, prejudicando as populações agrícolas que dependem de sua qualidade. O Seridó potiguar é uma região na qual os agricultores já enfrentam as dificuldades para a produção agrícola geradas pelas características do semiárido, como a ocorrência de secas periódicas e enxurradas. Para essa população rural, considerada vulnerável, a necessidade de adaptação às mudanças climáticas se apresenta como mais um grande desafio. Nesse sentido, o presente estudo buscou analisar as percepções dos agricultores sobre as variações e mudanças no clima e suas estratégias para lidar com o semiárido. O estudo foi realizado em 29 comunidades de quatro municípios da região por meio de entrevistas com atores locais e da aplicação de questionários com 241 agricultores. A percepção dos agricultores sobre as variações climáticas é bastante difusa, porém, eles afirmam que as mudanças podem ser observadas principalmente pela alteração dos períodos chuvosos e secos, bem como pela intensificação destes. Embora a região constitua um dos núcleos de desertificação identificados pelo Ministério do Meio Ambiente (2004), em geral as estratégias desenvolvidas para a convivência com a semiaridez são bem reduzidas, o que gera uma condição de vulnerabilidade que poderá ser agravada numa situação de mudanças climáticas mais profundas. A falta de assistência técnica e a escassez de recursos financeiros são apontadas como fatores limitantes para a adoção de estratégias de adaptação. Sendo assim, é necessário promover e estimular as estratégias de convivência com o semiárido e de adaptação às mudanças climáticas na região do Seridó potiguar.

Palavras-chave: percepção; semiárido; agricultura familiar. 
ABSTRACT The occurrence of climate change can increase the scarcity of natural resources on the semiarid regions of the planet, harming the agricultural populations who depend on its quality. The Serido in Rio Grande do Norte is a region where the farmers already face the difficulties of agricultural production generated by the characteristics of the semiarid climate, like the occurrence of periodic droughts and floods. For this vulnerable rural population, the need to adapt to climate changes is another major challenge. In this regard, the present study investigates the farmers' perceptions about climate variations and changes, and their strategies for dealing with the semiarid climate. The study was conducted at 29 communities in four counties of the potiguar's Serido through interviews with local actors and the application of questionnaires to 241 farmers. Farmers' perceptions on climate variability are very diffuse, but they claim that the changes can be observed mainly by the change of rainy and dry seasons, as well as the intensification of these events. Although the region constitutes one of desertification nucleus identified by the Ministry of Environment of Brazil (2004), in general the strategies developed for coping with the semiarid are very few, which creates a condition of vulnerability that may be worsened in a situation of climate change. The lack of technical and financial resources are identified as factors limiting the adoption of adaptation strategies. Therefore, it is necessary to promote and stimulate the strategies of coexistence with the semiarid and adaptation to climate change in the region of Serido.

Keywords: perception; semiarid; family farming.

\section{Introdução}

Nas últimas décadas as mudanças do clima e seus impactos no planeta se tornaram um dos desafios mais críticos e discutidos por cientistas, bem como pela sociedade em geral. De acordo com o estudo desenvolvido pelo Núcleo de Assuntos Estratégicos da Presidência da República (NAE), as mudanças climáticas já são percebidas por meio dos seguintes fatores: “[...] aquecimento global, maior frequência e intensidade de eventos climáticos extremos, alterações nos regime de chuvas, perturbações nas correntes marinhas, retração das geleiras e elevação do nível dos oceanos" (NAE, 2005, p. 13).

A agricultura é uma atividade vulnerável aos efeitos que as mudanças climáticas causam aos balanços hidrológicos, aos recursos naturais e a outros componentes dos ecossistemas no qual se desenvolvem (Smit \& Skinner, 2002; Apata et al., 2009). Portanto, independentemente da discussão sobre as causas das mudanças climáticas serem naturais ou antropogênicas, é necessário buscar estratégias de adaptação para o meio rural, principalmente para os pequenos agricultores que, por serem dependentes da produção agrícola e dos recursos naturais para a subsistência, sofrerão os impactos adversos das alterações climáticas (Mertz et al., 2009; Deressa et al., 2011).

Ainda sobre as mudanças climáticas, os cenários do Painel Intergovernamental sobre a Mudança do Clima - $\operatorname{IPCC}^{1}$ (2007) - preveem, para as regiões semiáridas, uma perda da biodiversidade em geral, o agravamento do quadro de desertificação ${ }^{2}$ e salinização ${ }^{3}$ das terras agrícolas, a redução da disponibilidade de água - e, com isso, grandes prejuízos para a produção agropecuária. Sendo assim, acredita-se que os agricultores familiares das regiões semiáridas são duplamente vulneráveis às mudanças climáticas: por um lado, pelo próprio grau de fragilidade social que historicamente caracterizou a agricultura familiar e, por outro, pelo fato de os agricultores habitarem regiões que podem ser fortemente afetadas.

O Seridó potiguar, localizado no interior do Estado do Rio Grande do Norte, encontra-se inserido na região semiárida do Nordeste brasileiro, caracterizada pela

\footnotetext{
${ }^{1}$ Sigla em inglês.

${ }^{2}$ Segundo o Programa de Ação Nacional de Combate à Desertificação e Mitigação dos Efeitos da Seca - PAN-Brasil (2004), a desertificação é o processo de degradação das terras nas zonas áridas, semiáridas e subúmidas secas, resultante de diferentes fatores como variações climáticas e atividades humanas, principalmente por causa do uso inadequado dos recursos naturais.

${ }^{3}$ De acordo com Dias et al. (2007), a salinização dos solos é um fenômeno que ocorre principalmente nas regiões áridas e semiáridas devido aos baixos índices de pluviosidade e às altas temperaturas, que provocam a evaporação da água, aumentando a disposição de sais na superfície do solo com o tempo.
} 
aridez do clima, pela deficiência hídrica e pela imprevisibilidade das chuvas. Além disso, conta com o agravante de estar localizado em uma área considerada um dos núcleos de desertificação do Brasil (MMA, 2004; Silva, 2006). Nessa região, as condições climáticas naturalmente rigorosas, aliadas às pressões antrópicas - pecuária extensiva, agricultura de sequeiro (praticada nos meses de chuva na região) com culturas e técnicas inadequadas, indústria extrativista da cerâmica e mineração -, resultam em áreas extremamente degradadas, e reduzem a capacidade adaptativa dos agricultores às mudanças climáticas futuras, aumentando a sua vulnerabilidade (Souza, 2006; Azevedo, 2007). Todos esses fatores afetam negativamente a produção agrícola familiar já fragilizada do Seridó.

A dimensão dos impactos das mudanças climáticas para a agricultura familiar, em geral, varia de acordo com as estratégias de adaptação adotadas em resposta às alterações (Gbetibouo, 2009). No entanto, segundo Maddison (2007), para a busca de estratégias adaptativas é necessário, primeiramente, que a percepção das alterações climáticas ocorra entre os afetados. Além disso, Vedwan e Rhoades (2001) acreditam que, devido às incertezas da modelação dos eventos climáticos e à escassez geral de dados de longo prazo em países em desenvolvimento, as pesquisas sobre as adaptações culturais - bem como o entendimento e percepções dos agricultores - assumem uma importância crítica.

Nesse sentido, o presente estudo buscou analisar o conhecimento e as percepções dos agricultores familiares do Seridó Potiguar sobre as variações climáticas ocorridas na região e também sobre o aquecimento global e as mudanças climáticas, além de verificar as estratégias adotadas para a adaptação às mudanças que foram percebidas (Maddison, 2007). O artigo também tem a pretensão de analisar quais características pessoais influenciam as percepções dos agricultores.

A fim de compreender essas questões, primeiramente foi abordada a temática das mudanças climáticas buscando referências sobre os cenários previstos para a região semiárida do Nordeste brasileiro. Em seguida, foram discutidos os conceitos e a importância do estudo da percepção ambiental, bem como as estratégias para realização desse tipo de estudo em comunidades rurais.

\section{As mudanças climáticas e os cenários para o semiárido brasileiro}

Segundo o glossário do IPCC, as mudanças climáticas ocorrem em decorrência de alterações internas no sistema climático ou nas interações entre seus elementos - e também podem ser causadas por forças externas, como fatores naturais e ações antrópicas (IPCC, 1995).

De acordo com o NAE (2005), os países em desenvolvimento são os mais vulneráveis às mudanças climáticas futuras, pois, mesmo na atualidade, enfrentam dificuldades para responder à variabilidade natural do clima; além disso, as populações desses países, por possuírem menos recursos financeiros, são as que enfrentam maiores dificuldades para a adaptação às mudanças. Segundo o referido estudo, o Brasil é um país que pode ser intensamente afetado pelas mudanças climáticas, uma vez que sua economia depende fortemente dos recursos naturais (NAE, 2005). Essa vulnerabilidade se manifesta de diversas formas, entre elas, no aumento da intensidade e frequência de secas e/ou enchentes que ameaçam a agricultura e a biodiversidade.

O Quarto e o Quinto Relatórios de Avaliação do Painel Intergovernamental sobre a Mudança do Clima (IPCC, 2007; 2013) apresentam os impactos projetados para este século, dentre os quais estão citados abaixo apenas os que atingem o Brasil e as regiões semiáridas:

Recursos hídricos: Até a metade do século XXI, o escoamento médio anual dos rios e a disponibilidade das águas poderão ser reduzidos em 10-30\% nos trópicos secos. As zonas afetadas pela seca provavelmente aumentarão em extensão e o risco de enchentes será maior devido aos fortes eventos de precipitação.

Ecossistemas: As mudanças climáticas - aliadas a outras mudanças globais, como a poluição e a sobreposição de recursos - irão comprometer a resiliência dos ecossistemas de forma sem precedentes, fazendo com que de 20 a 30\% das espécies de plantas e animais entrem em risco de extinção.

Segurança alimentar: As mudanças climáticas podem afetar todos os aspectos da segurança alimentar, incluindo o acesso aos alimentos, a utilização e a estabilidade dos preços. Um aumento nas temperaturas globais de aproximadamente $4^{\circ} \mathrm{C}$ em relação aos índices do final do 
século 20, aliado ao aumento da demanda por alimentos, colocaria a segurança alimentar regional e global em alto risco e esse risco é ainda maior em áreas de baixa latitude. Nas regiões secas e tropicais, a produtividade dos cultivos irá diminuir mesmo num cenário de pouco aumento da temperatura $\left(1-2^{\circ} \mathrm{C}\right)$. Além disso, as secas e enchentes irão afetar, principalmente, a produção agrícola dos setores de subsistência.

Zonas rurais: Grandes impactos são esperados para as áreas rurais por meio de alterações na disponibilidade e no abastecimento de água, segurança alimentar, renda agrícola, incluindo mudanças nas áreas de produção de cultura de alimentos e de outros produtos. Esses impactos podem afetar de forma desproporcional as regiões rurais mais pobres, como as propriedades lideradas por mulheres e aquelas com acesso limitado à terra, a tecnologias agrícolas, infraestrutura e educação.

Para o semiárido da América Latina, o IPCC (2007) prevê uma tendência de substituição da vegetação de terras semiáridas para uma vegetação adaptada às terras áridas - e uma perda significativa da biodiversidade em geral. Além disso, as alterações climáticas deverão agravar o quadro de salinização e desertificação das terras agrícolas, reduzindo a produtividade de diversas culturas importantes e da pecuária, comprometendo a segurança alimentar. As alterações nas precipitações também podem comprometer a disponibilidade de água para o consumo e para agricultura.

Utilizando dados do Instituto Nacional de Meteorologia (INMET), Salati et al. (2007) realizaram uma análise comparativa das temperaturas médias do Nordeste no período entre 1961 e 1990 e entre 1991 e 2004 e os resultados indicaram um aumento de $0.6^{\circ} \mathrm{C}$ nas temperaturas média e máxima e de $0.5^{\circ} \mathrm{C}$ na temperatura mínima entre os períodos estudados. A precipitação entre esses períodos sofreu uma redução de $153 \mathrm{~mm}$, o que representa uma diminuição de 11,6\% (Salati et al., 2007).

Um dos fenômenos climáticos que afetam a região semiárida do Brasil é o El Niño. Segundo Medeiros, o El Niño é "um fenômeno oceânico atmosférico que ocorre devido ao aumento anormal da temperatura na superfície do mar na costa Oeste da América do Sul durante o verão" (Medeiros, 2004, p. 41). O El Niño atua no Nordeste brasileiro influenciando e prolongando as secas - como as de 1932, 1983 e 1998 - e, se esse fenômeno aumentar em frequência e/ou intensidade, o semiárido ficará mais exposto a secas e/ou enchentes - além de ondas de calor mais recorrentes (Marengo, 2007).

O semiárido do Nordeste já é vulnerável à ocorrência de enchentes, como a que aconteceu em 2004, na qual caíram mais de $1.000 \mathrm{~mm}$ de água em apenas um mês (Marengo, 2007). Essas chuvas intensas provocam a morte de pessoas e animais, a diminuição ou a perda da produção, destruição de casas, barragens e açudes, além de deixarem várias famílias e comunidades ilhadas (Marengo, 2007).

Dentro de um cenário de altas emissões de $\mathrm{CO}_{2}, \mathrm{O}$ INPE prevê para o Nordeste um aumento de temperatura entre 1.5 e $5.5^{\circ} \mathrm{C}$. Já as previsões sobre o regime de chuvas, segundo Marengo et al. (2007), não são conclusivas. Enquanto alguns modelos climáticos apresentam reduções drásticas para os regimes de chuvas, outros apresentam aumento. Contudo, para o Nordeste - que já é a região com o menor número de dias chuvosos do Brasil - projeta-se que as chuvas serão mais fracas, com a ocorrência de chuvas intensas concentradas em curtos períodos (Marengo, 2007; Marengo et al., 2007).

Autores como Marengo (2007) e Nobre (2011) acreditam que o Bioma da Caatinga é um dos mais vulneráveis ao aumento das temperaturas globais, além de ser um dos mais ameaçados do país. Caso o aquecimento ocorra, seria transformado em "um tipo de semideserto com vegetação do tipo cactácea" (Marengo, 2007, p. 135).

Há, portanto, uma tendência de extensão da deficiência hídrica durante todo o ano para o Nordeste, ou seja, uma tendência para a "aridização" da região semiárida até o final do século XXI que afetará a agricultura de subsistência da região, podendo impossibilitar a sobrevivência da população, que migraria, gerando "ondas de refugiados ambientais" (Marengo, 2007, p. 138; Marengo et al., 2007).

\section{A percepção ambiental em comunidades rurais}

Diante dessa perspectiva de aridização do semiárido, agravada pelas mudanças climáticas, a agricultura pode ser duramente afetada, principalmente a pequena produção agrícola e os que dela dependem. Para com- 
preender as consequências que essas mudanças podem trazer, Weber (1997) acredita ser necessário, primeiramente, entender as percepções, julgamentos e ações dos agricultores a este respeito. Maddison (2007) explica que as percepções são importantes, pois, no processo de adaptação às mudanças climáticas, o primeiro passo é a percepção dos indivíduos de que essas mudanças estão ocorrendo.

A percepção ambiental se refere à forma com que as pessoas vivenciam e se relacionam com o ambiente no qual estão inseridas, considerando, além dos aspectos físicos, "também os aspectos psicossociais (cognição, afeto $^{4}$, preferências, etc.), socioculturais (significados, valores, estética) e históricos (contextos políticos, economia, etc.)" (Kuhnem \& Higuchi, 2011, p. 225).

Tuan (1980) acredita que muito do que percebemos está relacionado com o que valorizamos culturalmente e com a nossa necessidade de sobrevivência biológica, sendo a atitude uma "postura cultural" de posicionamento frente ao mundo. Portanto, dentro do processo de percepção, alguns fenômenos são registrados, enquanto outros são bloqueados como forma de responder aos estímulos externos (Tuan, 1980).

De acordo com Okomoto (2002), somos constantemente "bombardeados" por esses estímulos externos provenientes do meio ambiente natural, cultural e social. Diante desse "bombardeio", nossa mente seleciona os "aspectos de interesse" - e assim ocorrem a "percepção (imagem) e a consciência", que, somadas aos estímulos internos, resultam no comportamento.

Okomoto explica que a percepção dos estímulos é influenciada pelas barreiras que eles devem ultrapassar antes de serem interpretados. Esses obstáculos podem existir no meio ambiente, mas também podem ser naturais do homem, como a deficiência fisiológica, a faixa etária, o sexo ou diferenças culturais (Okomoto, 2002).

Dentro do paradigma compartilhado pela pesquisa em percepção ambiental (bem como das relações homem e ambiente), a compreensão que os indivíduos e/ou a coletividade possuem do meio ambiente - e, consequentemente, suas escolhas e comportamentos - é vista como a força maior na transformação e no modelamento desse espaço (Whyte, 1977). Contudo, o comportamento humano também é influenciado pelas características do ambiente em que vive (Kuhnem \& Higuchi, 2011). Nesse sentido, Whyte (1977) considera a pesquisa da percepção ambiental essencial e o ponto de partida para compreender as relações homem e ambiente.

Tuan (1980) também enfatiza a importância da pesquisa em percepção ambiental quando diz que a autocompreensão é fundamental para encontrar as soluções para os desafios ambientais, que não deixam de ser também humanos. Whyte (1977) acredita que a pesquisa ancorada nessa abordagem pode contribuir para o uso racional dos recursos, encorajando o envolvimento local no desenvolvimento e no planejamento como uma base para uma implementação mais eficiente de uma mudança apropriada. Nesse sentido, o conhecimento local pode representar um importante elemento para a compreensão dos mecanismos de adaptação já adotados tradicionalmente pelos agricultores familiares para a produção agrícola e também para a busca de estratégias e alternativas de convivência com o semiárido e de adaptação às mudanças climáticas.

Com relação à percepção ambiental relacionada ao clima, alguns estudos realizados mostram que os agricultores com maior experiência, o que frequentemente está associado à idade, estão mais propensos a perceber alterações climáticas (Maddison, 2007; Deressa et al., 2011). Para Deressa et al. (2011), outros fatores, como a exposição aos meios de comunicação em massa, renda, gênero, educação, acesso à assistência técnica e serviços de extensão, localização geográfica, dentre outros, podem afetar a percepção das mudanças climáticas.

Portanto, além da análise das percepções ambientais dos agricultores familiares do Seridó potiguar, com foco nas alterações climáticas - como explicado anteriormente-, buscou-se também avaliar quais fatores influenciam a percepção do clima e o conhecimento dos agricultores familiares sobre os temas das mudanças climáticas e do aquecimento global, além de verificar as estratégias adotadas para a adaptação e o planejamento da produção.

\footnotetext{
${ }^{4} \mathrm{O}$ elo afetivo entre a pessoa e o lugar ou ambiente físico é conceituado por Tuan (1980) como topofilia em sua obra Topofilia: um estudo da percepção, atitudes e valores do meio ambiente (Tuan, 1980, p. 5).
} 


\section{Metodologia}

A presente pesquisa é um dos resultados do Projeto "Mudanças Climáticas, Produção e Sustentabilidade: Vulnerabilidade e Adaptação em Territórios do Semiárido" da sub-rede Mudanças Climáticas e Desenvolvimento Regional (CDS/UnB) da Rede Brasileira de Pesquisas sobre Mudanças Climáticas Globais - Rede Clima.

A estratégia metodológica adotada consistiu na revisão da literatura sobre a questão das mudanças climáticas, sobre o conceito e a pesquisa em percepção ambiental e agricultura familiar; pesquisa de campo com a realização de entrevistas com lideranças locais dos municípios selecionados para a pesquisa e aplicação de questionários com 241 agricultores familiares, além da obtenção e análise dos dados secundários da região.

A metodologia da pesquisa de campo baseou-se nas orientações de Whyte (1977) na obra Guidelines for Field Studies in Environmental Perception (Orientações para pesquisa de campo em percepção ambiental) ${ }^{5}$ para os estudos em percepção ambiental. Segundo a autora, independentemente do foco da pesquisa em percepção ambiental, todas as técnicas de campo devem envolver uma combinação de três abordagens básicas complementares: observar, ouvir e fazer perguntas (Whyte, 1977).

Para a seleção de uma amostra representativa, os municípios selecionados para a pesquisa foram definidos buscando atender os seguintes critérios:

- a distribuição geográfica no território e o número de famílias por comunidade;

- o nível de organização política (mais organizada e menos);

- o nível de acesso à politica pública (maior inserção e menor);

- presença de diferentes estratégias produtivas e de comercialização;

- diversidades étnica (quilombolas) e socioeconômica;

- diversidade de formas de acesso à terra (assentamentos, pequenas propriedades, arrendatários);

- diversidade de formas de acesso à água (encanada, cisternas).
O município de Caicó foi incluído na pesquisa por possuir o melhor índice de desenvolvimento humano, maiores área e população em relação aos demais municípios e por desenvolver a agricultura irrigada; Parelhas apresenta grande diversidade produtiva, como indústria ceramista, produção agrícola e mineradoras; Acari possui uma grande parte de sua vegetação nativa preservada, tem uma alta organização política da associação dos produtores rurais, possui comunidades de pescadores e conta também com experiências agroecológicas; e Lagoa Nova está inserida na Serra de Santana, que tem características ambientais diferenciadas do sertão, possui uma produção mais diversificada por meio através da fruticultura, além de ter uma comunidade quilombola.

Para cada município, foram selecionadas as comunidades com produção agrícola relevante, com diferentes níveis de desenvolvimento agrícola e social e também de acordo com a indicação dos gestores locais. A quantidade de comunidades escolhidas para cada município foi definida de acordo com o tamanho da população. A partir dos critérios propostos, foram selecionadas as seguintes comunidades: Assentamento Perímetro Irrigado Sabugi Vilas I e II, Quixaba, Carrapateira, Barra da Espingarda e Inês Velha no município de Caicó; Domingas, Cachoeira e Sítio Cidade em Parelhas; Assentamento Bico da Arara, Vaca Brava e Gargalheiras em Acari, Macambira, Baixa Verde e Zé Milanez em Lagoa Nova.

Devido a dificuldades em encontrar os agricultores em suas residências durante o período da pesquisa, em algumas comunidades, e ao número reduzido de famílias, também foram realizadas entrevistas em algumas comunidades adjacentes às selecionadas em Parelhas, Caicó e Acari. Sendo assim, em Parelhas foram adicionadas as comunidades Sussuarana II, Salgadinho e Maracujá; em Caicó foram acrescentadas as comunidades Sítio Algodão, Sítio Várzea Cumprida, Domingas, Sítio Serraria, Barro Branco, Caridade, Sítio Inácio e, Sítio Riachão; e em Acari também foram entrevistados agricultores das comunidades Fazenda Parelhas, Santa Isabel, Bulhões e Moreira, totalizando assim 29 comunidades, sítios e fazendas.

A primeira etapa da pesquisa de campo foi realizada em outubro de 2011 e teve como objetivo o

${ }^{5}$ Traduzido pelas autoras. 
reconhecimento da região estudada. Os municípios selecionados foram visitados e foram realizadas entrevistas semiestruturadas com atores locais (prefeitos, secretários, membros de associações e sindicatos) e com alguns agricultores familiares com o objetivo de identificar os projetos e programas em andamento na região, diagnosticar e estabelecer critérios de seleção das comunidades-alvo. O trabalho de campo foi realizado por pesquisadores de áreas complementares, que atuaram no Projeto Mudanças Climáticas, Produção e Sustentabilidade: Vulnerabilidade e Adaptação em Territórios do Semiárido da Rede Clima.

A segunda etapa da pesquisa de campo foi realizada em novembro de 2011, na qual foram aplicados ques- tionários com 241 agricultores familiares da zona rural dos municípios selecionados. Foram realizadas perguntas relacionadas à observação dos padrões de temperatura e ocorrência de chuvas e/ou secas, sobre os danos causados por fatores climáticos e adaptações realizadas, alterações percebidas na flora e na fauna, sobre seus conhecimentos a respeito das mudanças climáticas e do aquecimento global, estratégias de adaptação ao clima, dentre outras questões relacionadas.

Para atingir os objetivos da pesquisa, as análises dos resultados dos questionários aplicados foram realizadas em quatro passos:

Primeiramente, foram analisados os resultados sobre as percepções dos agricultores familiares sobre

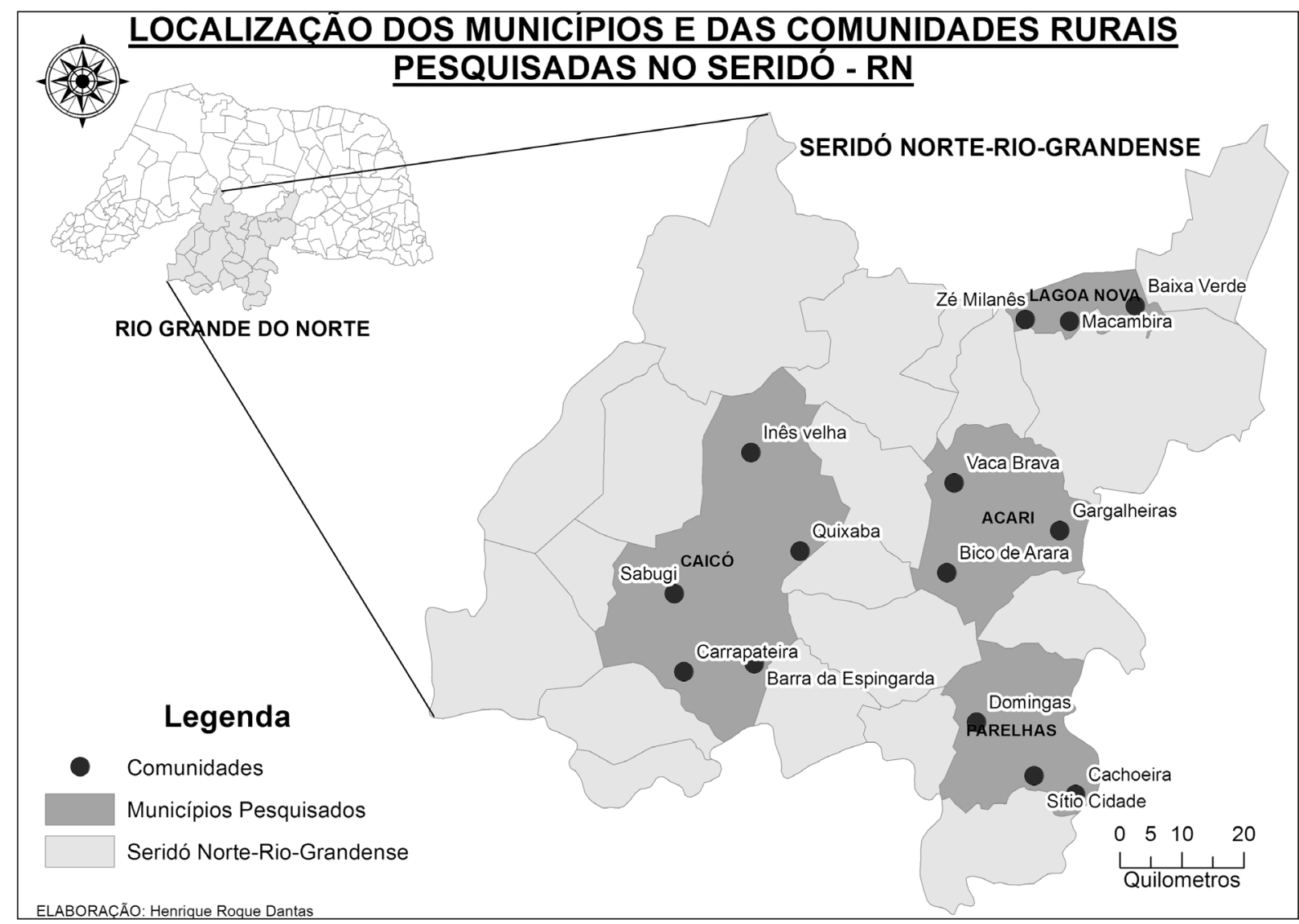

FIGURA 1 - Localização do Seridó com os municípios e as comunidades selecionadas para a pesquisa em destaque.

FONTE: Morais (2005) e Relatório parcial do Projeto "Mudanças Climáticas, Produção e Sustentabilidade: Vulnerabilidade e Adaptação em Territórios do Semiárido", área de estudo: Região do Seridó Potiguar - Rio Grande do Norte (não publicado). Adaptado. 
as alterações no clima e seus conhecimentos sobre as mudanças climáticas e aquecimento global.

No segundo momento, foi seguida a orientação de Deressa et al. (2011) de comparar as percepções dos agricultores com os dados climáticos, com o objetivo de analisar a precisão das percepções dos agricultores. Como no semiárido os desafios para a agricultura estão relacionados à ocorrência de secas e enchentes, as percepções foram comparadas aos dados pluviométricos relacionados aos anos de seca e de chuvas, obtidos pela EMPARN (Neves et al., 2010), referentes ao período de 1963 a 2009. Esse tipo de análise, na qual os dados climáticos são comparados com as percepções dos agricultores, já foi realizado em diversos estudos. Maddison (2007) realizou um estudo com o objetivo de determinar a habilidade em detectar as mudanças climáticas dos agricultores africanos, no qual foram utilizados dados de 11 países e mais de 9.500 agricultores, comparando a probabilidade de que o clima tenha mudado baseado na análise de dados estatísticos com a proporção de indivíduos que acreditam que essas mudanças no clima de fato ocorreram. O resultado indicou que um número significante de agricultores acreditam que as temperaturas subiram e que a precipitação declinou; no entanto, o autor encontrou equívocos ao comparar as percepções dos agricultores com os dados climáticos e afirmou que, muitas vezes, os registros climáticos disponíveis são menores que as memórias dos próprios agricultores. Vedwan e Rhoades (2001) pesquisaram como os agricultores do oeste do Himalaia indiano percebem a mudança climática, verificando a precisão das percepções por meio da comparação das alterações observadas pelos agricultores no calendário climático idealizado com os dados da queda de neve e das precipitações entre os anos de 1962-1996. Nesse caso, apesar de os agricultores perceberem mudanças no clima, eles ainda não perceberam alterações no calendário climático. Gbetibouo (2009) também realiza uma análise comparativa entre a percepção dos agricultores da Bacia do rio Limpopo, na África do Sul, com dados climáticos registrados em estações meteorológicas. Sua análise mostra que as percepções sobre as mudanças climáticas dos agricultores estão de acordo com os dados das estações.

A terceira análise foi realizada com o objetivo de verificar como determinadas características influenciam a percepção dos agricultores familiares sobre as alterações climáticas. Para isso, foram selecionadas algumas variáveis, como a localidade, a idade, o nível de educação, o tamanho da propriedade, o uso de irrigação, o acesso à assistência técnica dos agricultores e o tempo de experiência na propriedade (Gbetibouo, 2009).

Por último, foram analisadas as respostas dos agricultores sobre os danos sofridos devido ao clima, as estratégias de adaptação adotadas e de planejamento da produção para o ano seguinte.

\section{O Seridó potiguar}

O Seridó potiguar abrange uma área de $9.186,7 \mathrm{~km}^{2}$ (IBGE, 2010) no centro-sul do Estado do Rio Grande do Norte. O recorte regional do Seridó potiguar adotado para o presente estudo baseou-se na regionalização definida por Morais (2005), correspondente ao Seridó "historicamente construído" por meio de uma relação espaço-temporal "impregnada de conteúdo político, econômico e cultural", onde se manifestam os sentimentos de pertencimento e identidade da população. Dentro desse recorte, o Seridó é formado por 23 municípios: Caicó, Acari, Jardim do Seridó, Serra Negra do Norte, Currais Novos, Florânia, Parelhas, Jucurutu, Jardim de Piranhas, São João do Sabugi, Ouro Branco, Cruzeta, Carnaúba dos Dantas, Cerro Corá, São Vicente, São Fernando, Equador, Santana do Seridó, São José do Seridó, Timbaúba dos Batistas, Lagoa Nova, Ipueira e Tenente Laurentino Cruz (Morais, 2005, p. 26-27).

O Seridó potiguar possui 263.336 habitantes, dos quais 194.206 são residentes urbanos e outros 69.130 vivem em zonas rurais (Morais et al., 2010). Existem 9.970 estabelecimentos voltados para agricultura familiar, o que representa $80,6 \%$ dos estabelecimentos agrícolas da região. Esses estabelecimentos, porém, ocupam apenas $24,2 \%$ da área total dos estabelecimentos agrícolas, somando 145.075 ha. Dessa área, 15.797 ha (10,8\% do total) são ocupados por lavouras temporárias, outros 7.855 ha (5,4\%) são ocupados com lavouras permanentes e 72.397 ha $(49,9 \%)$ ocupados com pastagens (IBGE, 2006).

Durante a maior parte do século XX, o Seridó foi umas das principais áreas produtoras de algodão (ouro branco) do sertão nordestino, atividade que era conci- 
liada com o extrativismo e a criação de gado (Azevedo, 2007). Na década de 1970, a região passou a sofrer os efeitos de uma grande seca, que impossibilitou a agricultura tradicional de sequeiro e forçou o deslocamento maciço da população (Azevedo, 2007). Já nos anos de 1980, os problemas existentes - alto índice de mortalidade infantil, baixa expectativa de vida, déficit habitacional e em saneamento básico, elevadas concentrações de terra e renda - foram agravados pela escassez dos recursos hídricos e pelo colapso do sistema econômico baseado no complexo algodoeiro e policultor-pecuário e do ciclo minerador (Azevedo, 2007). Na década de 1990, a população rural passou a se dedicar à pecuária leiteira e à atividade ceramista e houve também a continuidade do ao êxodo rural (Azevedo, 2007).

Atualmente, no universo da agricultura familiar do Seridó, o cenário mais comum é a produção em sequeiro - ou seja, sem a utilização de irrigação e apenas durante o período chuvoso - de milho e feijão, voltada para a subsistência da família. Alguns agricultores também plantam nas vazantes de rios e riachos (realizada no entorno dos corpos d'água à medida que estes vão secando) e poucos utilizam a irrigação, na qual a água é trazida por meio de canais conectados a reservatórios, principalmente na época de estiagem (Silva et al., 2013).

A maior parte dos agricultores familiares do Seridó potiguar também se dedica à criação de animais. Além da pecuária, muitos criam galinhas, porcos, cabras e ovelhas, e alguns também pescam nas áreas com açudes.
A maior parte do rebanho é criada de forma extensiva, ou seja, os animais ficam soltos na caatinga; no entanto, alguns também fazem a criação de forma intensiva - na qual os animais ficam presos em chiqueiros ou currais - e também semi-intensiva, com os animais confinados durante uma parte do dia.

Silva et al. (2013, p. 96) trazem mais detalhes sobre a criação de animais da região ao explicar como é realizada a alimentação dos rebanhos de acordo com a época do ano:

A dieta dos animais no período da estiagem (julho a dezembro) é constituída de pasto de sequeiro (caatinga), que surge ao cair das primeiras chuvas, se estendendo até os primeiros meses de estiagem, dependendo do regime pluviométrico; ração de armazém (pasta de algodão, farelo de trigo, babaçu, casquinha, soja); pasto irrigado/ vazante e pasto molhado do riacho (capim: elefante, braquiara, ceará, tangana, taboca, taquari), rama (batata, feijão, cebola, mandioca); cactáceas (mandacaru, xique-xique, palma), sobras de comida (soro de queijo e palha de milho seco, alimento humano). A comercialização dos rebanhos é realizada principalmente por meio de atravessadores, diretamente ao açougue local e ao consumidor.

Seguem, na Tabela 1, abaixo os detalhes sobre a população, o número de comunidades e a produção de cada município pesquisado:

De acordo com dados apresentados pelo Plano de Desenvolvimento Sustentável da Região do Seridó do

TABELA 1 - Características dos municípios pesquisados.

\begin{tabular}{lllll}
\hline Município & $\begin{array}{l}\text { População } \\
\text { total (hab.) }\end{array}$ & $\begin{array}{l}\text { População } \\
\text { rural (hab.) }\end{array}$ & $\begin{array}{l}\text { Número total de } \\
\text { comunidades }\end{array}$ & Produção \\
\hline Parelhas & 20.354 & 3.270 & 27 comunidades & $\begin{array}{l}\text { Hortifruticultura, bovinocultura de cor- } \\
\text { te/leite e cerâmica }\end{array}$ \\
\hline Acari & 11.035 & 2.133 & $\begin{array}{l}17 \text { comunidades; } \\
4 \text { assentamentos; } \\
\text { 2 povoados (pescadores) }\end{array}$ & $\begin{array}{l}\text { Hortifruticultura; bovinocultura de lei- } \\
\text { te; piscicultura }\end{array}$ \\
\hline Caicó & 62.709 & 5.248 & 60 comunidades & $\begin{array}{l}\text { Bovinocultura de corte e leite; fruticul- } \\
\text { tura }\end{array}$ \\
\hline Lagoa Nova & 13.983 & 7.182 & $\begin{array}{l}23 \text { comunidades; } \\
6 \text { assentamentos }\end{array}$ & Fruticultura \\
\hline
\end{tabular}

FONTE: As autoras, 2012.

NOTA: Os dados sobre o número de comunidades e produção foram obtidos nas entrevistas realizadas com os atores locais. 
Rio Grande do Norte (SEPLAN, 2000), a temperatura média anual da região situa-se entre 26 e $28^{\circ} \mathrm{C}$, a insolação é de 3.240 horas/ano, a umidade relativa do ar gira em torno de $64 \%$ e a precipitação pluviométrica média anual varia entre 645 e $750 \mathrm{~mm}$, com uma taxa alta de evapotranspiração.

No Seridó, a estação chuvosa é curta e concentrada entre os meses de janeiro e maio ( $87 \%$ do total de precipitação total do ano), com chuvas esparsas e irregulares e possibilidade de ocorrência de enxurradas (Medeiros, 2004; Duque, 2004). A região apresenta elevada deficiência hídrica, principalmente nos meses entre junho e dezembro (Santos et al., 2010). Não há meses de excedente hídrico, apenas entre fevereiro e abril a região apresenta valores de deficiência hídrica iguais a zero na maior parte dos municípios (Santos et al., 2010).

\section{Resultados e discussão}

Durante a pesquisa de campo, foram entrevistados 241 agricultores nos quatro municípios selecionados. Desse total, 66 residem em Lagoa Nova, 60 em Parelhas, 49 em Acari e 66 em Caicó. Com relação ao gênero, $62,2 \%$ dos entrevistados são homens e 37,8\% mulheres. Com relação à idade, quase a metade $(44,4 \%)$ dos entrevistados está na faixa etária entre 40 e 60 anos, $26 \%$ têm acima de 60 anos e 11,6\% possuem 30 anos ou menos. A maior parte dos agricultores entrevistados mora na zona rural $(89,6 \%)$, uma pequena parcela reside nas zonas urbanas $(2,5 \%)$ e alguns entrevistados $(8 \%)$ não responderam sobre sua residência atual.

A maioria dos agricultores $(53,5 \%)$ realiza a produção em sequeiro, na qual os produtos mais cultivados são feijão, milho e mandioca, enquanto $33,2 \%$ produzem na vazante - onde também são cultivados o feijão, o milho, além do capim e a batata-doce, entre outros - e apenas $16,6 \%$ têm a produção irrigada, que é voltada para a produção de milho e frutíferas. A maior parte do que é produzido é destinado à subsistência da família. Os poucos agricultores que comercializam seus produtos são altamente dependentes de atravessadores, pois não possuem meios viáveis para transportar os produtos da zona rural aos municípios onde estes poderiam ser comercializados. Os atravessadores compram os pro- dutos a preços baixos, o que muitas vezes inviabiliza a produção e desmotiva os agricultores a obterem renda por meio da agricultura. No entanto, alguns conseguem se organizar de forma a comercializar em feiras locais e em mercados institucionais do Governo Federal por intermédio de programas como o Programa de Aquisição de Alimentos (PAA) e o Programa Nacional de Alimentação Escolar (PNAE).

A criação de animais é outra atividade desenvolvida pela maioria dos agricultores, especialmente a criação de aves para o consumo doméstico e de bovinos para a comercialização de carne e leite. Alguns agricultores também se dedicam à criação de suínos, ovinos e caprinos. Dos entrevistados, quase $60 \%$ desenvolvem a pecuária bovina, $67,6 \%$ criam aves, $24,48 \%$ possuem ovinos, 19,9\% criam suínos e apenas 9,9\% possuem criação de caprinos. A criação desses animais varia entre a forma extensiva, na qual os animais são criados soltos na propriedade, intensiva, na qual eles permanecem em currais ou chiqueiros, e semi-intensiva, na qual os animais permanecem confinados apenas durante uma parte do dia. Para as aves, a forma extensiva de criação é a mais comum. Já para os bovinos, caprinos e ovinos, a criação semi-intensiva é mais difundida, e os suínos geralmente são criados de forma intensiva. É comum que o agricultor desenvolva mais de um tipo de produção, seja ela agrícola ou criação de animais.

De forma geral, os agricultores familiares seridoenses vêm percebendo alterações climáticas na região, que incluem mudanças no regime de chuvas e aumento da temperatura. Ao serem questionados sobre a percepção de mudanças na estação chuvosa, mais de $80 \%$ dos agricultores responderam que notaram alterações. As mudanças mais relatadas foram chuvas mais fortes, imprevisibilidade e deslocamento da época das precipitações. A maior parte dos agricultores $(85,9 \%)$ também percebeu uma mudança na temperatura, na qual a maioria acredita que o clima está mais quente.

Para os agricultores, apesar de o clima ter esquentado, houve uma diminuição na ocorrência de secas e muitos também perceberam alterações nos meses que geralmente são mais frios ou quentes. De acordo com as entrevistas, a maior parte deles $(52,3 \%)$ afirmou ter percebido uma redução na frequência de anos secos, $16,6 \%$ não notaram nenhuma diferença e $15,8 \%$ disseram 
ter ocorrido um aumento dos anos secos. Grande parte $(48,1 \%)$ dos entrevistados notou mudanças relacionadas ao deslocamento dos meses frios e quentes - como, por exemplo, o início tardio do inverno ${ }^{6}$ ou chuvas em meses que geralmente não chove - e imprevisibilidade relacionada a essas ocorrências, o que atrapalha o planejamento dos agricultores. Outros $41,1 \%$ não notaram nenhuma mudança nos meses que geralmente são frios ou quentes.

Embora tenham percebido o aumento na intensidade e a imprevisibilidade das chuvas e da temperatura, além da redução na frequência de anos secos, a maior parte dos agricultores $(60,2 \%)$ acredita que, em geral, o clima se mantém o mesmo desde que chegaram à região, enquanto apenas $36,1 \%$ responderam que houve algum tipo de mudança no clima. Quando questionados se o clima melhorou ou piorou, mais de $40 \%$ disseram que piorou, o que também contradiz com os $60,2 \%$ que afirmaram que o clima se mantém o mesmo. Isso traz o questionamento sobre a indução das respostas, que pode ser considerada uma limitação do método do questionário direcionado, uma vez que os agricultores podem ter respondido de acordo com o que acreditavam que gostaria de ser escutado por parte dos entrevistadores, o que pode ser considerado uma limitação da metodologia adotada de questionário direcionado. Essa visão de que o clima "piorou", apesar de "se manter o mesmo", também pode refletir o "registro cultural" descrito por Tuan (1980), pois, apesar de o clima se manter o mesmo, é visto com negatividade pelos agricultores, que apresentam em suas respostas um desabafo sobre as dificuldades que são constantemente enfrentadas por causa do clima semiárido.

Nesse contexto, boa parte dos agricultores $(38,2 \%)$ acredita que, se as mudanças no clima continuarem ocorrendo, a produção agrícola será a principal afetada, enquanto $22,8 \%$ e $22,4 \%$ acreditam ser a saúde e a criação de animais, respectivamente, as mais afetadas.

Com relação ao conhecimento dos agricultores sobre os termos "Mudanças Climáticas" e "Aquecimento Global", os dados foram os seguintes: quando questionados se já ouviram falar em mudanças climáticas,
$55,2 \%$ dos entrevistados afirmaram conhecer o termo, embora $14,5 \%$ desse total não soubessem definir o que significa. Os que apresentaram alguma resposta, em geral relacionaram as mudanças climáticas ao desmatamento, à poluição, aos danos ao meio ambiente e ao "clima esquentando", enquanto alguns também acreditam que está relacionada com o "fim dos tempos"- expressão que ilustra a forte religiosidade presente na cultura seridoense. Já o termo "aquecimento global" é mais conhecido entre os agricultores, sendo que $64,3 \%$ afirmaram já terem ouvido falar sobre o conceito, embora $22,3 \%$ dos que declararam conhecer o termo não conseguissem defini-lo. Os agricultores relacionaram o aquecimento global ao desmatamento, à poluição e ao "aquecimento do clima"; além disso, também foram citados, como causadores ou efeitos do aquecimento global, as queimadas, o efeito estufa, a camada de ozônio, o derretimento das geleiras, dentre outros. Mais da metade dos agricultores tomou conhecimento desses termos por meio da televisão, no entanto, essas informações são transmitidas de uma forma superficial e não contextualizada com a realidade do semiárido. Além da televisão, outros meios menos citados foram o rádio, associações, cooperativas, sindicatos, igreja e entre amigos e familiares. Enfim, percebe-se que os agricultores em geral possuem pouco conhecimento sobre as mudanças climáticas e o aquecimento global e que a televisão não consegue supri-los com as informações mais aprofundadas sobre esses assuntos. Ainda maior é a deficiência de informações sobre como esses fenômenos climáticos podem impactar a região do Seridó e, consequentemente, a produção agrícola. Essa falta de conhecimento impede que os agricultores possam buscar e adotar estratégias de adaptação aos impactos que as mudanças climáticas e o aquecimento global podem causar nas regiões semiáridas.

Para verificar a memória das percepções dos anos mais secos e mais chuvosos, foi seguida a sugestão de Vedwan e Rhoades (2001) de utilizar dados climáticos e/ou pluviométricos, comparando-os com as respostas dos agricultores familiares. Os dados utilizados nessa pesquisa foram os dados pluviométricos obtidos com o

\footnotetext{
${ }^{6}$ Inverno no Nordeste brasileiro, nesse contexto, não se refere à estação do ano, mas ao período chuvoso que se distribui entre os seis primeiros meses do ano, a depender da área (Morais, 2005).
} 
documento "Análise Pluviométrica do Rio Grande do Norte. Período: 1963-2009”, realizado pela Empresa de Pesquisa Agropecuária do Rio Grande do Norte S.A. - EMPARN (Neves et al., 2010). O estudo citado foi realizado utilizando dados de postos pluviométricos e de estações meteorológicas da região, sendo a análise feita por meio da técnica dos quantis (Pinkayan, 1966 apud Neves et al., 2010) e classificação das séries nas categorias Muito Seco (MS), Seco (S), Normal (N), Chuvoso (C) e Muito Chuvoso (MC) (Neves et al., 2010).

Em se tratando da convergência entre as percepções dos agricultores e os dados da EMPARN, identificou-se a necessidade de verificar o grau de correlação entre as variáveis. Com base nos resultados dos questionários, os 241 agricultores familiares que participaram da pesquisa identificaram os anos de seca e anos de chuva que assolaram a região do Seridó Potiguar, sendo que cada entrevistado poderia apresentar mais de uma resposta, tanto para anos de seca quanto para anos chuvosos. Durante a aplicação de todas as entrevistas, não ocorreram, por parte dos entrevistadores, sugestões de datas, ficando em aberto a resposta por parte do entrevistado. A tabela abaixo apresenta os dados resultantes da pesquisa de campo, divididos em anos de seca e anos de chuva:

TABELA 2 - Número de respostas fornecidas pelos agricultores sobre os anos de chuva e anos de seca que marcaram a região.

\begin{tabular}{cccc}
\hline $\begin{array}{c}\text { Anos de seca } \\
\text { que marcaram } \\
\text { a região }\end{array}$ & $\begin{array}{c}\mathbf{N}^{\mathbf{0}} \text { de } \\
\text { respostas }\end{array}$ & $\begin{array}{c}\text { Anos de chuva } \\
\text { que marcaram } \\
\text { a região }\end{array}$ & $\begin{array}{c}\mathbf{N}^{\mathbf{0}} \text { de } \\
\text { respostas }\end{array}$ \\
\hline 1970 & 38 & 1964 & 12 \\
1980 & 14 & 1974 & 24 \\
1981 & 13 & 1984 & 21 \\
1982 & 15 & 1985 & 14 \\
1983 & 53 & 1994 & 20 \\
1990 & 15 & 2000 & 12 \\
1993 & 59 & 2004 & 54 \\
1997 & 10 & 2005 & 14 \\
1998 & 13 & 2006 & 12 \\
1999 & 11 & 2008 & 33 \\
2003 & 19 & 2009 & 25 \\
- & - & 2010 & 59 \\
- & - & 2011 & 61 \\
\hline
\end{tabular}

FONTE: Resultados da pesquisa de campo, 2012.
Considerando-se os dados apresentados, pode-se observar primeiramente que os últimos 10 anos foram bastante citados pelos agricultores, o que significa que, quanto mais antiga a ocorrência climática, mais difícil é mantê-la na memória dos agricultores. Mesmo assim, moradores mais idosos falam que, no passado, as secas eram mais severas, como as de 1932, 1933, 1958 e 1970. Inclusive, apesar de não constar na tabela acima por estar fora do período de abrangência do estudo da EMPARN, o ano de 1958 foi bastante citado pelos agricultores como um ano de seca marcante. O ano de 1970 também foi bem marcante para os agricultores. Um deles, morador de Lagoa Nova, chegou a relatar que perdeu oito filhos por causa da seca nesse ano. No entanto, pode-se constatar que a partir do momento em que os agricultores passaram a ter cisternas, a vulnerabilidade à seca foi bastante reduzida. A fala de um dos entrevistados de Lagoa Nova retrata essa realidade: "Passamos muita fome. Depois que chegou esse negócio de cisterna melhorou muito”.

Também se pode verificar que os últimos anos foram mais marcados pela ocorrência de chuvas. A Tabela 3 apresenta os resultados obtidos da classificação pluviométrica do Seridó potiguar entre os anos de 1963 e 2009, segundo estudo realizado pela Empresa de Pesquisa Agropecuária do Rio Grande do Norte - EMPARN (Neves et al., 2010) e segundo os agricultores entrevistados.

Com base nos dados da EMPARN, os anos de 1964, 1967, 1974, 1975, 1977, 1985, 1994, 2004 e 2008 foram os mais chuvosos e, desses nove anos, seis foram também citados pelos agricultores. Os anos chuvosos não citados pelos agricultores foram 1967, 1975 e 1977. Já os agricultores também apontaram os anos de 1984 e 2000, não citados pela EMPARN, como de chuva marcante.

Já os anos mais secos considerados pela EMPARN foram 1966, 1970, 1982, 1983, 1990, 1993, 1998 e 2001. E, entre os oito anos citados pela EMPARN, os agricultores concordaram em seis - apenas 1966 e 2001 não foram citados pelos agricultores. Em contrapartida, os agricultores também apontaram os anos de 1980, 1981, 1997, 1999 e 2003 como bastante secos; já esses anos foram citados como secos pela EMPARN, embora não como muito secos.

Apesar de alguns anos considerados secos ou chuvosos pela EMPARN não terem sido citados pelos 
TABELA 3 - Relação entre os dados da Empresa de Pesquisa Agropecuária do Rio Grande do Norte - EMPARN - e a opinião dos agricultores sobre os anos chuvosos e secos.

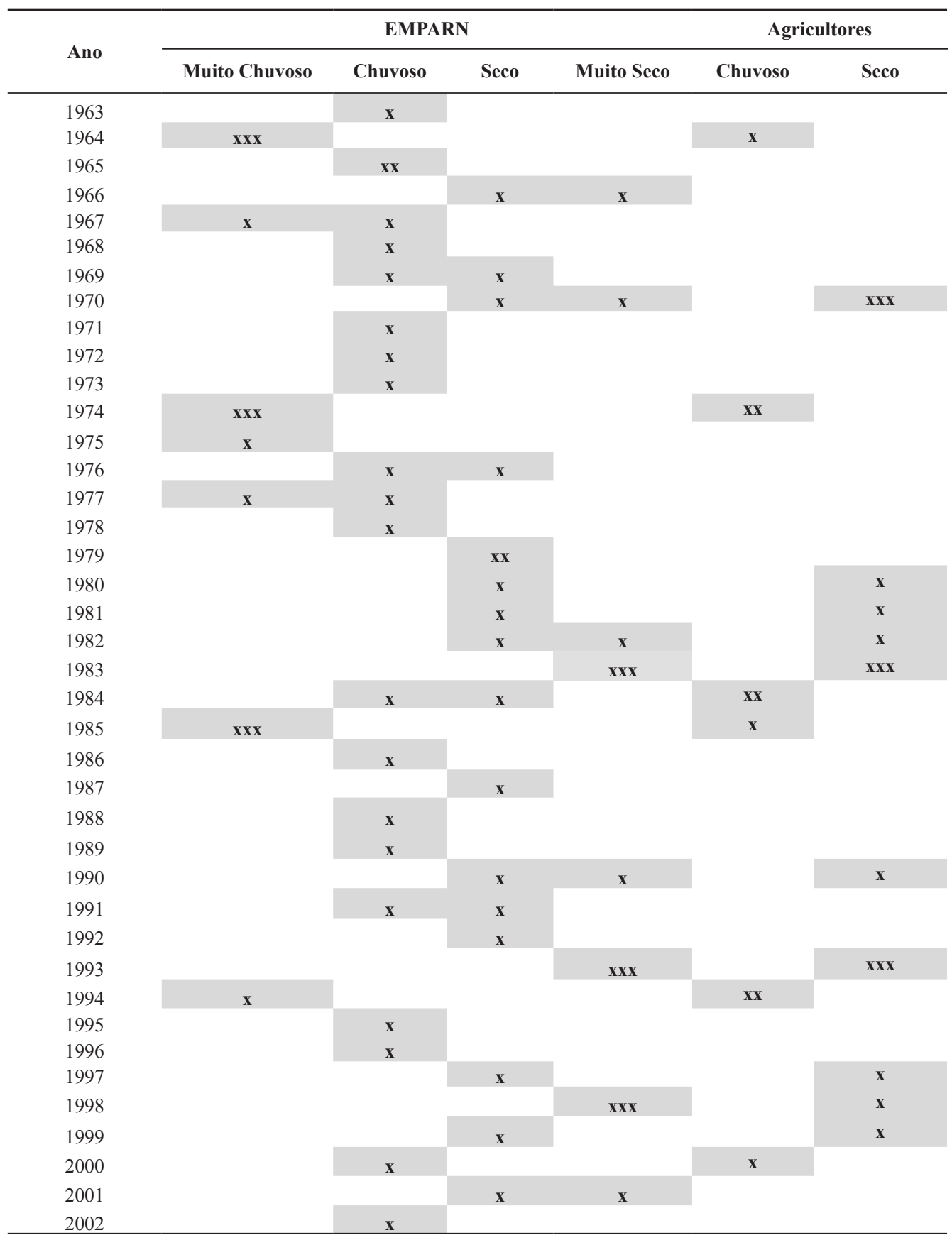

(Continua) 
(Tabela 3 - Conclusão)

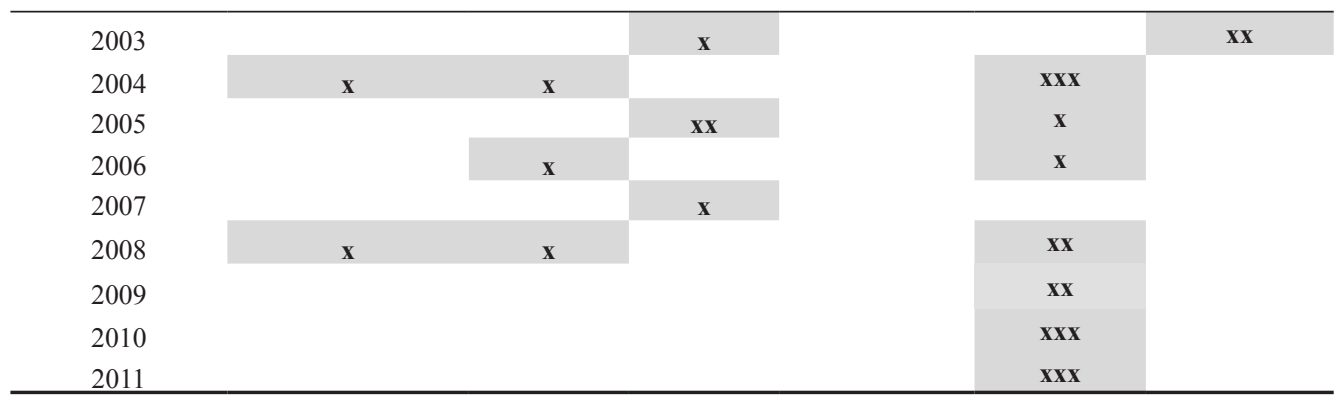

FONTE: Adaptado de Neves et al, 2010.

NOTA: Na coluna da EMPARN, a quantidade de " $x$ " marcada representa a intensidade de seca ou chuva no determinado ano. Na coluna dos agricultores, o " $x$ " representa a categoria climática mais citada no determinado ano.

agricultores e vice-versa, pode-se observar que os dados foram convergentes na maioria das vezes. Isso demonstra que, apesar de uma minoria dos agricultores se lembrar com precisão dos anos de seca ou chuva intensa, para muitos esses anos de clima mais crítico ficam guardados na memória pela forma com que afetam suas vidas.

Como citado anteriormente, alguns estudos realizados mostram que os agricultores com maior experiência, o que frequentemente está associado à idade, estão mais propensos a perceber alterações climáticas (Maddison, 2007; Deressa et al., 2011). Para Deressa et al. (2011), outros fatores, como gênero, educação, acesso à assistência técnica e serviços de extensão, localização geográfica, dentre outros, podem influenciar a percepção das mudanças climáticas.

Nesse sentido, a análise seguinte buscou verificar as diferenças nas percepções de acordo com determinadas características dos agricultores que tiveram percepções diferenciadas, como a localidade, a idade, o nível de educação, o tamanho da propriedade, o uso de irrigação, o acesso à assistência técnica dos agricultores e o tempo de experiência na propriedade. Portanto, primeiramente foram analisadas as respostas de acordo com os municípios. Em todos os municípios, cerca de $80 \%$ dos entrevistados perceberam mudanças na estação chuvosa. Parelhas foi o município no qual os agricultores mais perceberam um aumento nos anos secos, com $25 \%$ dos entrevistados, e Acari obteve a menor porcentagem (4\%). No entanto, em todos os municípios a maioria dos agricultores percebeu uma redução dos anos secos e mudanças na temperatura. Em Acari, os agricultores perceberam mais as mudanças no período dos meses frios e quentes, segundo eles, principalmente devido à imprevisibilidade das chuvas. Em Lagoa Nova, os agricultores, em sua maioria, perceberam mudanças na época de florir ou de dar frutos, diminuição da quantidade da produção e do número de animais selvagens. Nos outros municípios, os agricultores que tiveram essas percepções foram menos da metade.

Essa variação nas percepções pode ser explicada por Lagoa Nova ter uma produção diferenciada dos outros municípios, voltada para a fruticultura de caju e manga. Muitos agricultores desse município reclamaram que a safra do caju atrasou e que as flores das árvores estavam caindo devido ao excesso de vento causado pelo desmatamento e também pela ocorrência de pragas. Algumas lideranças locais também salientaram que está havendo um processo de desmatamento no município, principalmente dos cajueiros, cuja madeira é destinada às indústrias ceramistas de outros municípios da região. Outra diferença verificada nas respostas foi que os agricultores de Acari apresentaram um conhecimento maior sobre as mudanças climáticas e o aquecimento global. Talvez isso possa ser explicado pelo nível de envolvimento dos agricultores desta localidade com a Empresa de Assistência Técnica e Extensão Rural do Rio Grande do Norte (EMATER), que, juntamente com o poder municipal, faz um trabalho bem orientado neste 
sentido. Além disso, os agricultores de Acari são mais envolvidos em associações de moradores e com o Sindicato dos Trabalhadores Rurais do que os agricultores entrevistados nos outros municípios.

Com relação à idade do agricultor, o que se pode observar é que todas as faixas etárias perceberam uma mudança na estação chuvosa e na temperatura - e uma redução dos anos secos. Sobre a mudança no período dos meses frios e quentes, a idade não influenciou as respostas e, como foi visto, a maioria dos agricultores não percebeu alterações. Em todas as faixas etárias, a maior parte dos agricultores acredita que o clima se mantém o mesmo desde que chegaram à região, apenas os agricultores que nasceram entre 1930 e 1940 tiveram sua maioria respondendo que o clima não se mantém o mesmo. Quando questionados se o clima melhorou ou piorou, todas as faixas etárias tiveram a maioria respondendo que identificaram uma piora no clima. Em geral, não houve divergências significantes nas percepções de alterações do clima de acordo com a faixa etária. Porém, o que se pode verificar é que os agricultores mais jovens estão mais familiarizados com os temas das mudanças climáticas e do aquecimento global.

Com relação ao sexo do entrevistado, pode-se observar que homens e mulheres tiveram respostas bastante aproximadas para as questões sobre percepções e conhecimento sobre mudanças climáticas e aquecimento global.

A escolaridade dos agricultores também não influenciou significativamente quando se buscou compreender as percepções sobre as variações no clima, porém influencia quando se trata de saber o nível de conhecimento sobre as mudanças climáticas e o aquecimento global. Nesse caso, os mais jovens apresentaram maior conhecimento sobre essas questões.

Tanto os agricultores que possuem produção irrigada quanto os que não possuem responderam, em sua maioria, que notaram mudanças na estação chuvosa, porém, os que fazem irrigação apresentaram uma tendência maior a perceber mudanças na estação chuvosa. Com relação à frequência de anos secos, em ambos os casos, a maioria respondeu que percebeu uma redução, sendo que os agricultores que não irrigam apresentaram uma tendência maior a não perceber mudanças e/ou perceber também um aumento nos anos secos. A maior parte dos agricultores não percebeu mudanças nos períodos de meses quentes e frios, contudo, os que fazem irrigação apresentaram uma tendência maior do que os que não irrigam em perceber o deslocamento dos períodos. Os agricultores, em geral, também acreditam que o clima se mantém o mesmo desde que chegaram à região, no entanto, os que fazem uso da irrigação apresentaram uma tendência maior do que os que não irrigam a acreditar que o clima mudou. Os agricultores que fazem irrigação apresentaram também uma tendência significantemente maior em acreditar que o clima piorou, enquanto a opinião dos que não irrigam foi mais dividida entre as respostas. Acerca do conhecimento sobre as mudanças climáticas e o aquecimento global, pode-se verificar que os agricultores que possuem produção irrigada têm uma propensão maior a compreender esses termos.

Com relação às variações nas percepções sobre o clima de acordo com o tamanho da propriedade do agricultor, o que se pôde verificar foi que, quanto menor a propriedade, maior a tendência de o agricultor acreditar que houve uma mudança na época de florir ou dar frutos, o que talvez esteja mais relacionado com o fato de as menores propriedades estarem localizadas em Lagoa Nova, onde $72,7 \%$ dos entrevistados possuem estabelecimento com 10 hectares ou menos. Pode-se verificar também uma tendência maior dos agricultores com mais de 10 hectares em entender sobre as mudanças climáticas e o aquecimento global.

Também não foram observadas alterações significantes nas percepções das variações climáticas de acordo com o acesso à assistência técnica. Houve, sim, uma pequena tendência ao maior conhecimento dos termos mudanças climáticas e aquecimento global por parte dos agricultores que recebem assistência técnica, especialmente a provinda de amigos, familiares e ONGs. Como foi visto anteriormente, Acari é o município no qual os agricultores estão mais envolvidos com sindicatos, associações e com a EMATER e, consequentemente, os agricultores desse município apresentaram um maior conhecimento desses termos.

Com relação às percepções de acordo com o tempo e experiência do agricultor em sua propriedade, pode-se observar que os agricultores com maior tempo de vivência na região onde moram foram mais propensos a perceber uma redução na frequência de anos 
secos. Os mais experientes também perceberam mais o deslocamento e a imprevisibilidade dos meses frios e quentes. A porcentagem dos que acreditam que o clima se mantém o mesmo foi maior entre os com maior tempo de experiência, enquanto os moradores mais recentes apresentaram uma tendência maior a acreditar que o clima piorou. Entre os menos experientes o conhecimento sobre as mudanças climáticas e o aquecimento global foi maior, no entanto, esse fato provavelmente deve estar mais relacionado com a idade do agricultor do que com o seu tempo de experiência na propriedade. A Tabela 4 apresenta um resumo dos resultados das análises das percepções dos agricultores sobre o clima de acordo com as características selecionadas.

Com esses resultados, pode-se pressupor que as diferenças de percepções sobre as variações climáticas estão mais relacionadas com a localidade, com a forma de produção e com o tempo de experiência do agricultor com a propriedade. Já os conhecimentos sobre as mudanças climáticas são influenciados pelo acesso à educação, assistência técnica e renda, no caso, avaliada pelo tamanho das propriedades.

Como foi visto, a percepção de variações climáticas é fundamental para a adoção de estratégias adaptativas a essas mudanças; no entanto, vários fatores estimulam ou impedem as iniciativas dos agricultores. Nesse sentido, o presente artigo também buscou, por meio da análise das percepções, oferecer uma contribuição para a compreensão das estratégias de adaptação às mudanças climáticas que são adotadas pelos agricultores durante o planejamento da produção.

Para os agricultores familiares do Seridó potiguar, o clima aparece em segundo lugar, atrás da falta de recursos financeiros, como fator limitante para a produção agrícola. Quase 70\% dos agricultores responderam que já tiveram prejuízos por causa dos eventos climáticos. Esses prejuízos se apresentam em grande parte na perda de lavoura, perda de animais e redução da produtividade. A seca é o evento ambiental mais citado como causador de prejuízos, seguido das inundações causadas pelas cheias dos rios, de pragas e doenças.

TABELA 4 - Resumo dos resultados das análises das percepções de acordo com características dos agricultores.

\begin{tabular}{ll}
\hline Variável & Resultados \\
\hline Município & $\begin{array}{l}\text { Em Lagoa Nova foi percebida uma mudança na época de floração e de dar frutos, além da diminui- } \\
\text { ça da produtividade. Os agricultores de Acari apresentaram uma tendência maior em conhecer os } \\
\text { termos: mudanças climáticas e aquecimento global. }\end{array}$ \\
\hline Idade & $\begin{array}{l}\text { Resultados não conclusivos para as diferenças nas percepções. Observou-se que os mais jovens pos- } \\
\text { suem maior conhecimento sobre as mudanças climáticas e aquecimento global. }\end{array}$ \\
\hline Gênero & Percepções e conhecimentos semelhantes. \\
\hline Escolaridade & $\begin{array}{l}\text { Percepções semelhantes. O conhecimento sobre as mudanças climáticas e aquecimento global au- } \\
\text { menta de acordo com a escolaridade. }\end{array}$ \\
\hline Uso de irrigação & $\begin{array}{l}\text { Os agricultores que irrigam apresentaram uma tendência maior em acreditar que o clima piorou e um } \\
\text { maior conhecimento sobre as mudanças climáticas e o aquecimento global. }\end{array}$ \\
\hline Tamanho da & $\begin{array}{l}\text { Agricultores com maiores propriedades têm uma tendência maior em saber sobre as mudanças cli- } \\
\text { máticas e o aquecimento global. }\end{array}$ \\
\hline $\begin{array}{l}\text { Acesso à assistência } \\
\text { técnica }\end{array}$ & $\begin{array}{l}\text { Os agricultores que recebem assistência técnica apresentaram uma leve tendência a conhecerem } \\
\text { mais sobre as mudanças climáticas e o aquecimento global. }\end{array}$ \\
\hline $\begin{array}{l}\text { Tempo de experiência } \\
\text { na propriedade }\end{array}$ & $\begin{array}{l}\text { Os agricultores mais experientes perceberam mais a redução na frequência de anos secos e o des- } \\
\text { locamento e a imprevisibilidade dos meses frios e quentes. Enquanto eles acreditam que o clima se } \\
\text { mantém o mesmo, para os moradores mais recentes o clima piorou. }\end{array}$ \\
\hline
\end{tabular}

FONTE: Análise dos resultados dos questionários aplicados, 2012. 
Embora a grande maioria dos agricultores já tenha sofrido prejuízos por causa do clima, apenas 19\% deles afirmaram terem feito modificações na produção; no entanto, a modificação mais realizada foi o abandono de algum cultivo, o que não representa uma estratégia de adaptação, mas sim a dificuldade de atingir esse objetivo. A maior parte dos agricultores que não fizeram modificações respondeu que não acham necessário realizá-las, outros, porém, alegaram que o que impede a realização de modificações na produção e experimentos é a falta de recursos financeiros e de acesso à informação.

Uma forma de adaptação derivada do conhecimento tradicional dos agricultores sertanejos é a previsão do inverno por meio dos sinais da natureza ${ }^{7}$, conhecida como "experiências de inverno". Durante essas experiências, os que detêm esse conhecimento observam plantas, animais, astros e outros sinais da natureza, como a direção e a intensidade dos ventos, além de analisarem as datas, geralmente religiosas, das ocorrências climáticas, para tentar prever se o ano vai ser bom de inverno ou não. Apesar de ser uma tradição que vem perdendo espaço na cultura seridoense por falta de interesse dos jovens, ainda é muito comum encontrar agricultores que praticam e utilizam essas experiências para realizar o planejamento da produção agrícola. Segundo dados da pesquisa, $63 \%$ dos agricultores realizam algum tipo de observação - e para 50\% essas experiências servem para a organização do trabalho no campo.

${ }^{7}$ Ver Silva et al. (2013).

Quando questionados sobre as estratégias que geralmente adotam para definir o que será produzido no ano seguinte, a maior parte dos agricultores respondeu que a estratégia é sempre a mesma, ou seja, eles preferem investir nas espécies que já estão acostumados a plantar: o feijão, o milho e para alguns a mandioca - também porque acreditam que essas culturas são as que melhor se adaptam à região. Outra prática comum é esperar as primeiras chuvas para sentir como vai ser o ano e iniciar o cultivo. Em geral, se a perspectiva de inverno é boa, os agricultores expandem o plantio. Se a expectativa de inverno é ruim, os agricultores plantam menos ou até mesmo não plantam. No caso de ocorrência de seca, muitos dos que possuem gado optam por vender os animais para poder atravessar o período ruim.
Uma tecnologia social que melhorou bastante as condições de vida na região do Seridó potiguar, beneficiando-os com acesso à água, foi a implantação das cisternas. Segundo dados da pesquisa, aproximadamente $69,5 \%$ dos agricultores possuem cisternas em suas propriedades e a maior parte delas enche totalmente todos os anos. Muitos desses agricultores foram beneficiados pelo programa "Um Milhão de Cisternas" da Articulação do Semiárido Brasileiro em parceria com o Governo Federal; no entanto, pelo menos $22,4 \%$ deles tomaram a iniciativa de construir cisternas em suas propriedades antes da implementação desse programa.

Outras estratégias de adaptação pontuais foram encontradas no Seridó potiguar. Na comunidade Bico da Arara, em Acari, três famílias desenvolvem a produção agroecológica, por meio de uma horta mandala. Essa horta foi desenvolvida na busca de uma alternativa sustentável e viável para uma produção agrícola diversificada o suficiente para garantir a alimentação das famílias envolvidas e a renda com a venda dos produtos. A horta mandala agroecológica foi um projeto desenvolvido pela organização não governamental Agência Mandala; no entanto, atualmente, as famílias envolvidas com o projeto produzem de forma independente. Já em Parelhas, o Serviço Brasileiro de Apoio às Micro e Pequenas Empresas (SEBRAE) está implantando o Projeto Produção Agroecológica Integrada e Sustentável (PAIS) com algumas famílias da região. No entanto, essas experiências são bastante recentes e pontuais e, por isso, não refletem a realidade mais geral da agricultura familiar da região.

\section{Conclus̃̃es}

Os cenários estimados para as regiões semiáridas preveem o aumento da imprevisibilidade dos padrões de chuva e ocorrência de secas, elevação nas temperaturas, redução da biodiversidade e da disponibilidade de água. Esses impactos, além de causarem prejuízos para o meio ambiente, podem alterar consideravelmente as condições para o desenvolvimento da agricultura nessas regiões, forçando mudanças nos padrões de produção dos agricultores e a busca por estratégias de adaptação. Caso os agricultores não consigam se adaptar, podem 
ocorrer o aumento do êxodo rural, conflitos sociais entre comunidades que disputam o acesso aos escassos recursos naturais, além de graves prejuízos para a segurança alimentar dessas populações com o abandono dos cultivos, como identificado na pesquisa.

Os resultados dessa pesquisa mostraram que a maior parte dos agricultores percebeu alterações na estação chuvosa (chuvas mais fortes), na temperatura (clima mais quente), redução da ocorrência de anos secos e maior imprevisibilidade e/ou deslocamento dos meses quentes e frios. Os agricultores mais velhos relataram que ano passado as secas eram mais severas. Mais severas talvez porque a vulnerabilidade desses agricultores à seca era maior. A partir do momento em que passaram ter acesso às cisternas de captação de água da chuva, houve um aumento na resiliência desses agricultores aos efeitos da seca (Andrade et al., 2013). Por serem altamente vulneráveis às condições climáticas os agricultores seridoenses guardam na memória os anos de seca e chuvas que foram marcantes na região.

No ano de 2012, o Seridó, dentre outras regiões do semiárido potiguar, foi assolado por uma seca severa. $\mathrm{O}$ fato curioso é que no ano anterior, durante a pesquisa de campo realizada em novembro de 2011, os agricultores foram questionados sobre suas perspectivas para o ano seguinte e a maioria respondeu que até aquele momento as experiências de inverno estavam indicando um ano de "bom inverno". Todas as previsões, tanto as feitas pelos sertanejos como pela Empresa de Pesquisa Agropecuária do Rio Grande do Norte - EMPARN, mostravam um ano regular de inverno (Silva et al., 2013). Segundo Silva et al. (2013), isso não quer dizer que os agricultores e os meteorologistas não tenham credibilidade em suas previsões, mas que o tempo da região é algo difícil de prever. O IPCC (2013) explica que as secas do Nordeste geralmente estão associadas com o El Niño, mas que nesse ano, especificamente, a seca ocorreu no período da La Niña.

Já a problemática das mudanças climáticas ainda é uma novidade para a maior parte dos agricultores. Enquanto muito afirmaram que desconhecem os termos mudanças climáticas e aquecimento global, outros que já ouviram falar, geralmente por meio da televisão, não entendem ao certo o que significa e que consequências a ocorrência dessas mudanças pode acarretar para a produção agrícola na região. Quase a metade dos agricultores não tem co- nhecimento sobre as mudanças climáticas e o aquecimento global, em geral, e os que já ouviram falar nesses termos apresentaram dificuldades em explicar seus significados.

Para os agricultores, a falta de recursos financeiros e as adversidades climáticas são os principais desafios para o desenvolvimento da agricultura e, apesar de a maioria já ter sofrido prejuízos por causa do clima, poucos realizaram alterações na produção. Os agricultores preferem plantar as culturas com as quais já estão acostumados (feijão e milho), pois acreditam que essas culturas se adaptam às condições da região. Caso esperem um inverno fraco, a estratégia dos agricultores se resume em plantar menos e, para os que possuem gado, em caso de seca, os animais são vendidos. Conclui-se que, de forma geral, as estratégias de adaptação adotadas não estão relacionadas com a perspectiva das mudanças climáticas e intempéries do clima, mas sim com o costume local de buscar formas de lidar com as secas.

Esses dados mostram que os agricultores apresentam dificuldades em enfrentar as ameaças das mudanças climáticas, primeiro, por ser um tema ainda pouco conhecido entre eles, segundo, pela falta de informações e recursos para a adoção de estratégias de adaptação às variações climáticas já ocorrentes. Isso demonstra a necessidade de programas que visem informar, sensibilizar, preparar e oferecer oportunidades para que os agricultores possam aumentar sua capacidade de adaptação às mudanças climáticas dentro do paradigma da convivência com o semiárido. Para isso, é preciso compreender melhor os cenários das mudanças climáticas para a região, bem como as estratégias de adaptação já adotadas. É necessário que os agricultores estejam mais engajados e aptos a aplicar formas mais sustentáveis de uso da terra, que possam garantir a resiliência social e ambiental em tempos adversos.

Faz-se necessária a realização de novos estudos qualitativos mais aprofundados para a compreensão da capacidade adaptativa dos agricultores familiares seridoenses e as possíveis estratégias de adaptação às mudanças climáticas, que sejam coerentes com o paradigma da sustentabilidade e da convivência com o semiárido. Nesse contexto, sugere-se que sejam estudados os métodos utilizados pelos agricultores para se adaptarem às variações climáticas, os fatores que influenciam suas escolhas e as barreiras enfrentadas para a adaptação. 


\section{Referências}

Andrade, A. J. P. de; Souza, C. R. de; Silva, N. M. da. A vulnerabilidade e a resiliência da agricultura familiar em regiões semiáridas: o caso do Seridó Potiguar. Campo-território: Revista de Geografia Agrária, Uberlândia, 8(15), 1-30, fev. 2013.

Apata, T. G.; Samuel, K. D.; Adeola, A. O. Analysis of Climate change Perception and Adaptation among Arable Food Crop Farmers in South Western Nigeria. In: International Association of Agricultural Economics. Beijing, China, 2009.

Azevedo, F. F. Entre a cultura e politica: uma geografia dos "currais" no sertão do Seridó Potiguar. Uberlândia, Tese (Doutorado em Geografia) - UFU, 2007.

Deressa, T. T.; Hassan, R. M.; Ringler, C. Perception of and adaptation to climate change by farmers in the Nile basin of Ethiopia. Journal of Agricultural Science, 149(1), 23-31, 2011.

Dias, N. da S. et al. Salinização do solo por aplicação de fertilizantes em ambiente protegido. Irriga, 12(1), 2007.

Duque, J. G. Solo e água do polígono das secas. 6. ed. Fortaleza: Banco do Nordeste do Brasil, 2004.

Gbetibouo, G. A. Understanding Farmers Perceptions and Adaptations to Climate Change and Variability: The Case of the Limpopo Basin, South Africa. International Food Policy Research Institute, Discussion Paper 00849, 2009.

IBGE. Censo agropecuário 2006. Rio de Janeiro: Ministério do Planejamento, Orçamento e Gestão, 2006.

Censo Demográfico 2010. Disponível em: <http:// www.censo2010.ibge.gov.br>. Acesso em: ago. 2012.

IPCC. Climate Change: a glossary by the Intergovernmental Panel on Climate Change (1995). Disponível em: <http:// www.ipcc.ch/pdf/glossary/ipcc-glossary.pdf $>$. Acesso em: maio 2012.

Summary for Policymakers. In: Climate Change 2007: Impacts, Adaptation and Vulnerability. Contribution of Working Group II to the Fourth Assessment Report of the Intergovernmental Panel on Climate Change. Cambridge: Cambridge University Press, 2007.

Climate Change 2014: Impacts, Adaptation, and Vulnerability. Contribution of Working Group II to the Fifth Assessment Report of the Intergovernmental Panel on Climate Change. Cambridge: Cambridge University Press, 2014. Versão final.
Kuhnem, A.; Higuchi, M. I. G. Percepção ambiental. In: Cavalcante, S.; Elali, G. A. Temas básicos em Psicologia Ambiental. Petrópolis: Vozes, 2011.

Maddison, D. J. The Perception of and Adaptation to Climate Change in Africa. 2007. Disponível em: <http://papers.ssrn. com/sol3/papers.cfm?abstract id $=1005547>$. Acesso em: mar. 2012 .

Marengo, J. A. Mudanças climáticas globais e seus efeitos sobre a biodiversidade: caracterização do clima atual e definição das alterações climáticas para o território brasileiro ao longo do século XXI. v. 1. 2 ed. Brasília: Ministério do Meio Ambiente, 2007.

et al. Caracterização de clima atual e definição das alterações climáticas para o território brasileiro ao longo do século XXI. Sumário Técnico. 2007.

Medeiros, G. L. D. de. A desertificação do semiárido nordestino: o caso da região do Seridó Norte-Riograndense. Mossoró, Dissertação (Mestrado em Desenvolvimento e Meio Ambiente) - UFRN, 2004.

Mertz, O. et al. Farmers' Perceptions of Climate Change and Agricultural Adaptation Strategies in Rural Sahel. Environmental Management, 43(5), 804-816, 2009.

MMA. Programa de Ação Nacional de Combate à Desertificação e Mitigação dos Efeitos da Seca. Brasília: Edições MMA, 2004. 242 p.

Morais, I. R. D. Seridó norte-rio-grandense: uma geografia da resistência. Caicó: Editora do Autor, 2005.

et al. A desertificação no Seridó Potiguar. In: Moreira, E.; Targino, I. (Org.). Desertificação, desenvolvimento sustentável e agricultura familiar: recortes no Brasil, em Portugal e na África. João Pessoa: Editora Universitária da UFPB, 2010. p. $65-84$.

NAE. Mudança de Clima, Vol. I: Negociações internacionais sobre a mudança de clima; vulnerabilidade, impactos e adaptação à mudança de clima. Cadernos $N A E$, Brasília, Núcleo de Assuntos Estratégicos da Presidência da República, NAE-SECOM, 2005.

Neves, J. A.; Melo, S. de B.; Sampaio, E. V. de S. B. Análise pluviométrica do Rio Grande do Norte: período: 1963-2009. Natal: EMPARN, 2010. 
Nobre, P. Mudancas climáticas e desertificação: os desafios para o Estado brasileiro. In: Lima, R. C. C.; Cavalcante, A. de M. B.; Marin, A. M. P. (Ed.). Desertificação e mudancas climáticas no semiárido brasileiro. Campina Grande: Instituto Nacional do Semiárido, 2011.

Okomoto, J. Percepção ambiental e comportamento: visão holística da percepção ambiental na arquitetura e na comunicação. São Paulo: Mackenzie, 2002.

Salati, E.; Campanhol, T.; Villa Nova, N. Tendências das variações climáticas para o Brasil no século XX e balanços hídricos para cenários climáticos para o século XXI. Relatório 4. Brasília: Ministério do Meio Ambiente, 2007.

Santos, A. S. dos et al. Estimativa do balanço hídrico climático para a microrregião do Seridó - Estado do Rio Grande do Norte. In: Anais do $16^{\circ}$ Congresso Brasileiro de Meteorologia, Belém, 2010.

SEPLAN. Rio Grande do Norte. IICA. Plano de desenvolvimento sustentável do Seridó. Volume 1 (Diagnóstico). Caicó - RN, 30 de setembro de 2000.

Silva, N. M. da; Andrade, A. J. P. de; Souza, C. R. de. O sertanejo e as experiências de inverno no Seridó Potiguar. Desenvolvimento e Meio Ambiente, Curitiba, 27, 87-107, jan./jun. 2013.
Silva, R. M. A. Entre o combate à seca e a convivência com o semiárido: transições paradigmáticas e sustentabilidade do desenvolvimento. Brasília, Tese (Doutorado em Desenvolvimento Sustentável) - UnB, 2006.

Smit, B.; Skinner, M. Adaptation Options in Agriculture to Climate Change: A Typology. Mitigation and Adaptation Strategies for Global Change, 7(1), 85-114, 2002.

Souza, I. S. V. (Ed.). Agricultura familiar na dinâmica da pesquisa agropecuária. Brasília: Embrapa Informação e Tecnologia, 2006.

Tuan, Y. Topofilia: um estudo da percepção, atitudes e valores do meio ambiente. São Paulo: Difel, 1980.

Vedwan, N.; Rhoades, R. E. Climate change in the Western Himalayas of India: a study of local perception and response. Climate Research, 19(2), 109-117, 2001.

Weber, E. U. Perception and Expectation of Climate Change: Precondition for Economic and Technologic Adaptation. In: Bazerman, M. H et al. (Org.). Environment, Ethics and Behavior. São Francisco: The New Lexington Press, 1997.

Whyte, A. V. T. Guidelines for fields studies in Environmental Perception. Paris: UNESCO/MAB, 1977. 